\title{
KARAKTER AGRONOMI SORGUM VARIETAS SAMURAI II FASE VEGETATIF YANG DITANAM PADA JARAK TANAM BERBEDA
}

\author{
G. M. Dudato, Ch. L. Kaunang*, M. M. Telleng, C. I. J. Sumolang \\ Fakultas Peternakan Universitas Sam Ratulangi, Manado, 95115
}

\begin{abstract}
ABSTRAK
Penelitian ini bertujuan untuk mengetahui karakter agronomi Sorgum Varietas Samurai II fase vegetatif dengan jarak tanam berbeda. Penelitian ini menggunakan Rancangan Acak Lengkap (RAL) dengan 4 perlakuan yang terdiri dari JT1: jarak tanam $70 \mathrm{~cm} \mathrm{x} 40 \mathrm{~cm}$, JT2: jarak tanam $50 \mathrm{~cm}$ x $30 \mathrm{~cm}$, JT3: jarak tanam 30 cm x $20 \mathrm{~cm}$ dan JT4: jarak tanam $10 \mathrm{~cm} \mathrm{x}$ $10 \mathrm{~cm}$, masing-masing perlakuan terdiri dari 5 ulangan. Variabel yang diukur adalah karakter agronomis yaitu tinggi tanaman, jumlah daun, lebar daun, dan panjang daun. Hasil analisis menunjukkan bahwa perlakuan jarak tanam memberikan pengaruh yang berbeda sangat nyata $(\mathrm{P}<0,01)$ terhadap tinggi tanaman, jumlah daun, lebar daun dan panjang daun. Hasil uji berbeda nyata jujur menunjukkan bahwa jarak tanam $70 \mathrm{~cm}$ x $40 \mathrm{~cm}$ menghasilkan tinggi tanaman, jumlah daun, lebar daun dan panjang daun yang lebih tinggi dibandingkan dengan jarak tanam $50 \mathrm{~cm} \mathrm{x}$ $30 \mathrm{~cm}, 30 \mathrm{~cm} \times 20 \mathrm{~cm}$ dan $10 \mathrm{~cm} \times 10 \mathrm{~cm}$. Disimpulkan bahwa jarak tanam $70 \mathrm{~cm}$ x 40 $\mathrm{cm}$ memberikan karakteristik agronomi tertinggi dengan menghasilkan tinggi tanaman, jumlah daun, lebar daun dan panjang daun yang tertinggi.
\end{abstract}

Kata Kunci: sorgum, jarak tanam, agronomi

Korespondensi (Corresponding Author)

Email: charleskaunang@unsrat.ac.id
ABSTRACT

AGRONOMIC

CHARACTERISTIC OF

VEGETATIVE PHASE SORGUM

SAMURAI II VARIETY IN

DIFFERENT PLANTING SPACE. The purpose of this research to determine the agronomic characteristic of Samurai II Sorghum with different planting space. This experiment was conducted using Completely Randomized Design (CRD). The treatment consisted of four planting space, (1) $70 \mathrm{~cm} \mathrm{x} 40 \mathrm{~cm}$, (2) $50 \mathrm{~cm} \times 30$ $\mathrm{cm}$, (3) $40 \mathrm{~cm} \mathrm{x} 20 \mathrm{~cm}$, and (4) $10 \mathrm{~cm} \mathrm{x} 10$ $\mathrm{cm}$, each treatment had five replications. Data were analyzed using analysis of variance and HSD test. The variables measured were agronomic characteristic indicated by plant height, number of leaf, width of leaf and length of leaf. The results showed that different planting space were significant different $(\mathrm{P}<0.01)$ on plant height, number of leaf, width of leaf and length of leaf. HSD test showed that planting space $70 \mathrm{~cm}$ x $40 \mathrm{~cm}$ were significant $(\mathrm{P}<0.01)$ have higher plant height, number of leaf, width of leaf and length of leaf than planting space $50 \mathrm{~cm} \mathrm{x}$ $30 \mathrm{~cm}, 40 \mathrm{~cm} \times 20 \mathrm{~cm}$, and $10 \mathrm{~cm} \times 10 \mathrm{~cm}$. It can be concluded that planting space 70 $\mathrm{cm} \times 40 \mathrm{~cm}$ have the highest agronomic characteristic by producing the highest plant height, number of leaf, width of leaf and length of leaf.

Key words: sorghum, planting space, agronomic 


\section{PENDAHULUAN}

Hijauan merupakan pakan pokok ternak ruminansia yang berperan penting bagi pertumbuhan, produksi dan reproduksi. Untuk mencapai pertumbuhan ternak ruminansia yang optimal, harus ditunjang dengan penyediaan pakan yang cukup, baik kualitas, kuantitas maupun kontinuitasnya (Hajar et al., 2019). Salah satu jenis hijauan yang potensial dikembangkan sebagai pakan ruminansia adalah sorgum. Sorgum termasuk dalam family graminae, berpotensi untuk dibudidayakan secara komersial di Indonesia karena memiliki berbagai keunggulan diantaranya memiliki tingkat adaptasi yang cukup tinggi terhadap perubahan iklim (Yusuf et al., 2017), lebih tahan terhadap kekeringan dibanding tanaman jagung dan rumput gajah, sehingga berpotensi dikembangkan di kawasan kering, dapat di ratun sampai 4 kali dalam setahun, tahan genangan air sehingga tanaman ini dapat tumbuh dimusim hujan maupun musim kemarau (Sirappa, 2013). Sorgum potensial dikembangkan sebagai sumber karbohidrat (Yahfi et al., 2017).

Salah satu jenis sorgum yang gencar dikembangkan saat ini adalah sorgum Samurai II. Jenis sorgum ini telah dirilis oleh Badan Tenaga Nuklir Nasional
(BATAN) tahun 2013, memiliki keunggulan antara lain umur berbunga \pm 63 hari, umur panen \pm 113 hari, sifat tanaman tidak beranak tapi dapat diratun, tinggi tanaman $\pm 198.7 \mathrm{~cm}$, bentuk daun agak lebar dan memanjang, bentuk malai lonjong (elips), warna biji putih bening, bobot 100 biji \pm 27.4 gram, ukuran biji relatif kecil, tahan rebah, potensi hasil biomasa total \pm 28.6 ton/ ha, limbahnya dapat dimanfaatkan sebagai pakan dan multi fungsi.

Keunggulan-keunggulan tanaman sorgum tersebut harus didukung dengan teknik budidaya yang tepat. Teknik budidaya dengan meningkatkan kerapatan tanam pada tanaman sorgum merupakan salah satu upaya untuk peningkatan hasil produksi (Sitorus et al., 2015), masih jarang dibudidayakan di Indonesia (Syarifah, 2015) padahal potensinya sangat baik untuk memenuhi kebutuhan pakan yang masih didominasi pakan impor (Pithaloka et al., 2015).

Faktor - faktor yang mempengaruhi pertumbuhan tanaman adalah faktor genetik (faktor dalam) dan faktor lingkungan (faktor luar). Salah satu faktor lingkungan adalah jarak tanam atau tingkat kepadatan. Tingkat kepadatan tanaman yang tinggi akan mempengaruhi pertumbuhan per individu tanaman, karena dapat menghambat perkembangan vegetatif dan menurunkan hasil panen akibat 
menurunnya laju fotosintesis dan perkembangan daun (Gardner et al., 1991). Semakin rapat jarak tanam maka produktivitas hijauan akan menurun karena terjadi kompetisi antar tanaman dalam penyerapan hara, kebutuhan air, dan penangkapan cahaya matahari untuk fotosintesis (Sitorus et al., 2015)

Dalam upaya meningkatkan produksi tanaman sorgum sebagai pakan dan efisiensi penggunaan lahan dapat dilakukan dengan pengaturan jarak tanam, sehingga perlu dilakukan penelitian untuk memperoleh jarak tanam yang ideal.

\section{MATERI DAN METODE PENELITIAN}

\section{Waktu dan Lama Penelitian}

Penelitian ini dilaksanakan pada bulan Maret 2020 sampai bulan Mei 2020 dilahan perkebunan kelurahan Paniki Bawah Kec. Mapanget.

\section{MateriPenelitian}

Materi yang digunakan pada penelitian ini meliputi bahan dan alat. Bahan yang digunakan: Benih Sorgum Samurai II, pupuk kandang, urea, TSP, KCL. Alat yang digunakan: timbangan, thermometer, meteran, gunting, tali, patok, cangkul, sekop, kamera, kantong plastik.

\section{ProsedurPenelitian}

\section{Persiapan lahan:}

Lahan yang digunakan dalam penelitian ini diolah secara manual, dibersihkan dari rumput liar dan gulma, pembalikan tanah dan penggemburan. Kemudian dilakukan pencangkulan sebelum penanaman dan pemberian pupuk kandang dengan dosis 2 ton/ha (Sriagtula, et al. 2018). Plot - plot penelitian dibuat dengan ukuran $3 \mathrm{~m}$ x $3 \mathrm{~m}$.

\section{Penanaman:}

Empat belas hari setelah pengolahan tanah dilakukan penanaman benih sorgum dengan cara tugal. Benih ditanam pada petakan berukuran $3 \mathrm{~m}$ x $3 \mathrm{~m}$ dengan jarak tanam sesuai perlakuan, yaitu JT1: 70 x 40 cm, JT2: 50 x $30 \mathrm{~cm}$, JT3 30 x $20 \mathrm{~cm}$ dan JT4: 10 x $10 \mathrm{~cm}$. Tiap lubang ditanam $4-5$ benih sorgum dengan kedalaman $3 \mathrm{~cm}$. Setelah benih berkecambah dan tumbuh normal kemudian dilakukan penjarangan dengan menyisakan dua tanaman per lubang tanam.

\section{Pemeliharaan:}

Pemupukan dilakukan 15 hari setelah tanam (HST), pupuk yang diberikan berupa campuran urea, TSP, $\mathrm{KCl}$ dengan perbandingan 4:3:2 (g/g/g) dengan dosis $270 \mathrm{~kg} \mathrm{ha}^{-1}$ (Sugianto, 2015). Pemeliharaan dilakukan dengan penyiraman dua kali sehari dan pembersihan gulma pada plot penanaman.

\section{Pengamatan:}

Pengamatan dilakukan tiap hari sampai umur 8 minggu setelah tanam 
(mst). Dilakukan pencatatan suhu, dan setiap dua minggu sekali dilakukan pengukuran tinggi tanaman, jumlah daun, lebar daun dan panjang daun. Tanaman sampel dipilih secara acak. Setiap petak dipilih 5 tanaman sampel untuk pengamatan agronomi.

\section{RancanganPercobaan}

Percobaan dilakukan menggunakan Rancangan Acak Lengkap (RAL) yang terdiri dari 4 perlakuan dan 5 ulangan, sehingga terdapat 20 unit percobaan. Rancangan perlakuan sebagai berikut:

$\mathrm{JT} 1=70 \times 40 \mathrm{~cm}$

$\mathrm{JT} 2=50 \times 30 \mathrm{~cm}$

JT3 $=30 \times 20 \mathrm{~cm}$

JT4 $=10 \times 10 \mathrm{~cm}$

\section{Variabel yang diukur}

Pengamatan dilakukan pada tanaman contoh yang dipilih. Prosedur pengamatan mengacu pada Descriptors for Sorghum (IBPGR / ICRISAT 1993). Karakter agronomis yang diamati pada fase pertumbuhan vegetative $(8 \mathrm{mst})$ yaitu:

a. Tinggi tanaman $(\mathrm{cm})$

Diukur dari atas permukaan tanah hingga daun tertinggi pada fase vegetatif.

b. Jumlah daun (helai)

Jumlah daun dihitung pada saat 8 mst, daun yang berwarna hijau.

c. Lebar daun $(\mathrm{cm})$ diukur saat $8 \mathrm{mst}$, dari kiri kekanan dari bagian daun terlebar pada daun ke lima.

d. Panjang daun $(\mathrm{cm})$ diukur saat $8 \mathrm{mst}$, dari pangkal daun sampai ujung daun.

\section{HASIL DAN PEMBAHASAN}

Hasil penelitian yang telah dilakukan mengenai pengaruh perlakuan jarak tanam terhadap karakteristik agronomi yang dinyatakan dengan tinggi tanaman, jumlah daun, lebar daun dan panjang daun disajikan pada Tabel 1 .

\section{Pengaruh Perlakuan Terhadap Tinggi Tanaman}

Pengaruh perlakuan jarak tanam terhadap tinggi tanaman Sorgum varietas Samurai II yang dipanen pada fase vegetatif dapat dilihat pada Tabel 1.

Tinggi tanaman berkisar 125,61 cm pada jarak tanam $10 \mathrm{~cm}$ x $10 \mathrm{~cm}$ sampai dengan 151,52 cm pada jarak tanam $70 \mathrm{~cm}$ x $40 \mathrm{~cm}$. Hasil ini sama dengan penelitian dari Simanjutak et al. (2016) yang mendapatkan tinggi tanaman sorgum dengan perlakuan jarak tanam berbeda pada umur 2 bulan berkisar $139,95 \mathrm{~cm}$ sampai dengan 150, $25 \mathrm{~cm}$, tetapi lebih rendah dari penelitian Syarifah (2015) yang mendapatkan tinggi tanaman sorgum dengan perlakuan jarak tanam berbeda pada umur 2 bulan berkisar 209,30 $\mathrm{cm}$ sampai dengan $222,20 \mathrm{~cm}$. 
Tabel 1. Karakteristik Tanaman Sorgum Varietas Samurai II Pada Jarak Tanam Yang Berbeda.

\begin{tabular}{lcccc}
\hline \multirow{2}{*}{ Variabel } & \multicolumn{4}{c}{ Jarak Tanam } \\
\cline { 2 - 5 } & JT1 & JT2 & JT3 & JT4 \\
\hline Tinggi tanaman (cm) & $151,52^{\mathrm{a}}$ & $145,65^{\mathrm{b}}$ & $140,66^{\mathrm{c}}$ & $125,61^{\mathrm{d}}$ \\
Jumlah daun (helai) & $5,20^{\mathrm{a}}$ & $4,20^{\mathrm{b}}$ & $4,35^{\mathrm{b}}$ & $4,15^{\mathrm{b}}$ \\
Lebar daun (cm) & $5,93^{\mathrm{a}}$ & $5,05^{\mathrm{b}}$ & $4,92^{\mathrm{c}}$ & $4,87^{\mathrm{d}}$ \\
Panjang daun (cm) & $74,92^{\mathrm{a}}$ & $72,83^{\mathrm{b}}$ & $66,41^{\mathrm{c}}$ & $62,58^{\mathrm{d}}$ \\
\hline
\end{tabular}

Keterangan : Superskrip yang berbeda pada baris yang sama menunjukkan berbeda sanga nyata $(\mathrm{P}<0,01)$

Hasil analisis keragaman 2014).

menunjukkan bahwa perlakuan jarak tanam memberikan pengaruh yang berbeda sangat nyata $(\mathrm{P}<0,01)$ terhadap tinggi tanaman. Uji BNJ menunjukan bahwa perlakuan jarak tanam $70 \mathrm{~cm}$ x $40 \mathrm{~cm}$ menghasilkan tinggi tanaman yang berbeda sangatnyata $(\mathrm{P}<0.01)$ lebih tinggi dari jarak tanam 50 $\mathrm{cm} \times 30 \mathrm{~cm}$, jarak tanam $30 \mathrm{~cm}$ x $20 \mathrm{~cm}$ dan jarak tanam $10 \mathrm{~cm}$ x $10 \mathrm{~cm}$.

Tanaman yang ditanam pada jarak tanam yang lebih jauh, yang berarti tingkat kepadatan tanaman yang lebih rendah, akan mendapatkan lebih banyak sinar matahari dan unsur hara tanpa persaingan, sehingga menghasilkan peningkatan panjang dan lebar daun.

Sorgum merupakan tanaman C4 yang mampu memanfaatkan intensitas cahaya tinggi karena itu tanaman mampu memanfaatkan cahaya dengan efisien, sehingga proses fotosintesis bisa berjalan dengan baik (Capriyati dan Thohari,

\section{Pengaruh Perlakuan Terhadap Jumlah Daun}

Pengaruh perlakuan jarak tanam terhadap jumlah daun tanaman Sorgum varietas Samurai II yang dipanen pada fase vegetatif dapat dilihat pada Tabel 1. Jumlah daun tanaman sorgum berkisar 4,15 helai pada jarak tanam $10 \mathrm{~cm}$ x $10 \mathrm{~cm}$ sampai dengan 5,20 helai pada jarak tanam $70 \mathrm{~cm}$ x $40 \mathrm{~cm}$. Hasil ini lebih rendah dari penelitian Telleng et al. (2015) yang mendapatkan jumlah daun tanaman sorgum berkisar 6,33 helai sampai dengan 8,43 helai, dan penelitian (Syarifah 2015) yang mendapatkan jumlah daun tanaman sorgum dengan perlakuan jarak tanam berbeda pada umur 2 bulan berkisar 7,82 helai sampai dengan 11,05 helai.

Hasil analisis keragaman menunjukkan bahwa perlakuan jarak tanam memberikan pengaruh yang berbeda sangat 
nyata $(\mathrm{P}<0,01)$ terhadap panjang daun. Uji BNJ menunjukan bahwa perlakuan jarak tanam $70 \mathrm{~cm} \quad$ x $40 \mathrm{~cm}$ menghasilkan panjang daun yang berbeda sangat nyata $(\mathrm{P}<0.01)$ lebih panjang dari jarak tanam 50 $\mathrm{cm} \times 30 \mathrm{~cm}$, jarak tanam $30 \mathrm{~cm}$ x $20 \mathrm{~cm}$, dan jarak tanam $10 \mathrm{~cm} \times 10 \mathrm{~cm}$.

Tingkat kepadatan tanaman yang tinggi akan mempengaruhi pertumbuhan per individu tanaman, karena dapat menghambat perkembangan vegetatif dan menurunkan hasil panen akibat menurunnya laju fotosintesis dan perkembangan daun (Gardner et al., 1991). Peningkatan jumlah dan luas daun berarti semakin banyak penyerapan radiasi matahari. Hal iniberakibat pada proses fotosintesis, sehingga semakin banyak energi yang dihasilkan untuk pertumbuhan tanaman (Capriyati dan Thohari, 2014).

\section{Pengaruh Perlakuan Terhadap Lebar Daun}

Pengaruh perlakuan jarak tanam terhadap lebar daun tanaman Sorgum varietas Samurai II yang dipanen pada fase vegetatif dapat dilihat pada Tabel 1. Lebar daun tanaman sorgum berkisar $4,87 \mathrm{~cm}$ pada jarak tanam $10 \mathrm{~cm}$ x $10 \mathrm{~cm}$ sampai dengan 5,95 cm pada jarak tanam $70 \mathrm{~cm} \mathrm{x}$ $40 \mathrm{~cm}$. Hasil ini lebih rendah dari penelitian Telleng et al. (2015) yang mendapatkan jumlah daun tanaman sorgum berkisar $8,27 \mathrm{~cm}$ sampai dengan $8,73 \mathrm{~cm}$.
Hasil analisis keragaman menunjukkan bahwa perlakuan jarak tanam memberikan pengaruh yang berbeda sangat nyata $(\mathrm{P}<0,01)$ terhadap lebar daun. Uji BNJ menunjukan bahwa perlakuan $70 \mathrm{~cm} \mathrm{x}$ $40 \mathrm{~cm}$ menghasilkan lebar daun yang berbeda sangat nyata $(\mathrm{P}<0.01)$ lebih tinggi dari jarak tanam $50 \mathrm{~cm}$ x $30 \mathrm{~cm}$, jarak tanam $30 \mathrm{~cm} \times 20 \mathrm{~cm}$, dan jarak tanam 10 $\mathrm{cm} \times 10 \mathrm{~cm}$.

Tingkat kepadatan tanaman yang tinggi akan mempengaruhi pertumbuhan per individu tanaman, karena dapat menghambat perkembangan vegetatif dan menurunkan hasil panen akibat menurunya laju fotosintesis dan perkembangan daun (Gardner et al, 1991). Peningkatan jumlah dan luas daun berarti semakin banyak penyerapan radiasi matahari. Hal ini berakibat pada proses fotosintesis, sehingga semakin banyak energi yang dihasilkan untuk pertumbuhan tanaman (Capriyati dan Thohari, 2014).

\section{Pengaruh Perlakuan Terhadap Panjang Daun}

Pengaruh perlakuan jarak tanam terhadap panjang daun tanaman Sorgum varietas Samurai II yang dipanen pada fase vegetatif dapatdilihat pada Tabel 1. Panjang daun tanaman sorgum berkisar $62,58 \mathrm{~cm}$ pada jarak tanam $10 \mathrm{~cm}$ x $10 \mathrm{~cm}$ sampai dengan 74,92 cm pada jarak tanam $70 \mathrm{~cm} \mathrm{x}$ $40 \mathrm{~cm}$. Hasil ini lebih rendah dari 
penelitian Telleng et al. (2015) yang mendapatkan jumlah daun tanaman sorgum berkisar 95,52cm sampai dengan 107,76 $\mathrm{cm}$.

Hasil analisis keragaman menunjukkan bahwa perlakuan jarak tanam memberikan pengaruh yang berbeda sangat nyata $(\mathrm{P}<0,01)$ terhadap panjang daun. Uji BNJ menunjukan bahwa perlakuan jarak tanam $70 \mathrm{~cm}$ x $40 \mathrm{~cm}$ menghasilkan panjang daun yang berbeda sangat nyata $(\mathrm{P}<0.01)$ lebih panjang dari jarak tanam 50 $\mathrm{cm} \times 30 \mathrm{~cm}$, jarak tanam $30 \mathrm{~cm}$ x $20 \mathrm{~cm}$, dan jarak tanam $10 \mathrm{~cm}$ x $10 \mathrm{~cm}$.

Pertumbuhan daun tanaman antara lain dapat disebabkan oleh tinggihnya kandungan nutrisi tanah dan faktor fotosintesis. pada perlakuan jarak tanam 70 $\mathrm{cm}$ x $40 \mathrm{~cm}$ dengan jumlah tanaman dalam petak sebanyak 81 tanaman kurang bersaing dibandingkan dengan perlakuan jarak tanam $50 \mathrm{~cm}$ x $30 \mathrm{~cm}$, jarak tanam 30 $\mathrm{cm} \times 20 \mathrm{~cm}$, dan jarak tanam $10 \mathrm{~cm} \times 10$ $\mathrm{cm}$. Hal ini juga dapat dilihat dari warna daun tanaman sorgum samurai II yang lebih hijau pada jarak tanam $70 \mathrm{~cm} \mathrm{x} 40 \mathrm{~cm}$ dibandingkan pada perlakuan jarak tanam $10 \mathrm{~cm} \times 10 \mathrm{~cm}$. Jarak tanam mempengaruhi lingkungan iklim mikro untuk tananam dalam penggunaan unsur hara, air radiasi cahaya matahari (Harjadi, 1996)

\section{KESIMPULAN}

Jarak tanam $70 \mathrm{~cm} \mathrm{x} 40 \mathrm{~cm}$ sorgum varietas samurai II fase vegetatif memberikan karakteristik agronomi tertinggi dengan menghasilkan tinggi tanaman, jumlah daun, lebar daun dan panjang daun yang tertinggi.

\section{DAFTAR PUSTAKA}

Capriyati, R. dan D.K. Tohari. 2014. Pengaruh jarak tanam dalam tumpangsari sorgum manis (Sorghum bicolor L. Moench) dan Dua Habitus Wijen (Sesamum indicum L.) terhadap pertumbuhan dan hasil. Vegetalika 3(3): $49-62$

Gardner E. J.,R.B. Pearce, dan R.L. Mitchell 1991. Fisiologi Tanaman Budidaya (Terjemahan Herawati Susilo) Universitas Indonesia Press. Hal 155 dan 269

Hajar, H., L. Abdullah, D. Diapari. 2019 Pengaruh Jarak Tanam pada pertumbuhan beberapa varietas sorgum Hybrid sebagai sumber pakan. Jurnal Ilmu dan Teknologi PakanTropis. 6 (2) : 283-287

Harjadi, SS. 1996. Pengantar Agronomi. Gramedia Pustaka Utama. Jakarta

IBPGR; ICRISAT. 1993. International Board for Plant Genetic Resources; International Crops Research Institute for the Semi-Arid Tropics. Descriptors for Sorghum [ Sorghum bicolor (L.) Moench]. International Board for Plant Genetic Resources, Rome, Italy; International Crops Research Institute for the Semi- Arid Tropics, Patancheru, India. 1-44p.

Pithaloka, S.A., Sunyoto, M. Kamal, dan 
K.F. Hidayat. 2015. Pengaruh kerapatan tanam terhadap pertumbuhan dan hasil beberapa varietas sorgum (Sorghum bicolor (L) Moench). J. Agrotek Tropika 3(1): 56-63

Simanjutak, W., E. Purba, T. Irmansyah. 2016. Respons pertumbuhan dan hasil sorgum (Sorghum bicolor (L.) Moench) terhadap jarak tanam dan waktu penyiangan gulma. Jurnal Agroeko teknologi, 4(3): 2034 2039

Sirappa, M.P. 2013. Prospects for developing Sorgum in Indonesia as an alternative commodity for food, feed and Industrial. Jurnal Litbang Pertanian 22: 133-140

Sitorus, C.G.E., Sunyoto, M.S. Hadi, dan M. Kamal. 2015. Pengaruh kerapatan tanam terhadap pertumbuhan dan hasil tanaman (Sorghum bicolor (L) Moench) pada system tumpang sari ubi kayu (Manihot esculenta Crantz). J. Agrotek Tropis (3): 332-340

Sriagtula R., P.D.M.H. Karti, L. Abdullah. 2016. Growth biomass and nutrient production of brown midrib sorghum mutant lines at different harvest time. Pakistan Journal of Nutrition 15: 524-531

Sugianto, Nurbaiti, Deviona. 2015. Variabilitas genetic dan heritabilitas karakter agronomis beberapa genotype sorghum manis (Sorghum bicolor L. Moench) koleksi Batan. JOM Faperta. 2(1): 1-13

Syarifah, N.L. 2015. Pengaruh Beberapa Jarak Tanam Terhadap Produksi Sorgum (Sorghum bicolor (L.) Moench). Skripsi. Fakultas Pertanian, IPB. Bogor
Telleng, M.M., L. Abdullah, I.G. Permana, P.D.M.H. Karti, K.G. Wiryawan. 2015. Growth and productivity of different sorghum varieties cultivated with indigoferain intercropping system. Proceeding of the 3rd International Seminar on Animal Industry, Bogor, 17-18 September 2015

Yahfi, M.A., N.E. Suminarti, H.T. Sebayang. 2017. Pengaruh waktu dan frekuensi pengendalian Gulma pada pertumbuhan dan hasil Tanaman Sorgum (SBL Moench). Jurnal Produksi Tanaman 5(7): 1213-1219

Yusuf, A.C., R. Soelistyono, Sudiarso 2017. Kajian kerapatan tanam dengan berbagai arah baris pada pertumbuhan dan hasil tanaman sorgum (Sorghum bicolor (L) Moench). Jurnal Biotropika 5(3): 86-89 